\section{Is a 1-Year Residency Program Long Enough to Prepare Hospital Pharmacists for Practice?}

\section{THE "PRO" SIDE}

Before answering the question posed for this issue's Point Counterpoint debate, I ought to make it clear that my response to this question will be unapologetically biased, grounded as it is in my personal philosophy of education and my reflections on pharmacist training over the past 25 years or so. In responding, I will endeavour to be very clear about what I understand the question to be. I will also define what I expect a 1-year pharmacy residency program to do and what I believe residency-trained pharmacists will be able to do upon graduation, effective January 2010. Finally, I will explain why I believe that a 1-year pharmacy practice residency is adequate for its intended purposes.

By taking the "pro" side of this debate, I do not of course mean to say that there are major problems with the quality of Canadian entrylevel pharmacist education. In my experience, current entry-level education does exactly what it is intended to do: it prepares pharmacists to enter practice in any setting. At the present time, the term "minimally competent" describes the "pass" level for persons holding an entry-level pharmacy degree in Canada. ${ }^{1,2}$ From that level of preparation, pharmacists are expected to acquire and maintain competence and to evolve personal knowledge and skills to proficient or even expert levels in the service of their patients and communities. ${ }^{3}$ That this does not always occur is an issue for another Point Counterpoint debate.

It should also be mentioned that in responding to this question in the affirmative, I do not subscribe to the outmoded notion that pharmacy practice residencies prepare pharmacists for practice in hospitals. I am unconvinced that hospital patients require a higher level of skill from their pharmacist than patients served by pharmacists in the community. Many so-called "hospital patients" now receive care in the "community", and so-called "hospital pharmacy practice" is no longer conducted exclusively in hospitals or by "hospital pharmacists". In fact, the term "hospital" was removed from the Canadian definition of "pharmacy residency" more than a decade ago. As an educator, my bottom line is this: all pharmacists apply the same core competencies and have equal responsibility to grow skills to the levels required for continuing practice-the rest is just geography.

So, to go back to the preparation of pharmacists for practice: the Canadian Hospital Pharmacy Residency Board's Accreditation Standard 2010 will assure society that it can expect accredited pharmacy practice residency programs to refine the professional competence of their graduates and to help those graduates to achieve proficiency in providing direct patient care. ${ }^{4,5}$ In other words, graduates of accredited pharmacy practice residencies will exhibit professional maturity in the service of patients and within their professional, personal, and learning communities. ${ }^{2,3,6-8}$ Pharmacists exhibit professional maturity when they are able to provide timely advice about or solutions for complex, ill-defined (drug-related or other) problems proficiently, using an ethical framework. $^{3,6,8,9}$ Lest terms like "professional maturity", "competence", or "proficiency" obscure my position, let me make it abundantly clear what I mean: I want residency graduates to expect more of themselves as pharmacy professionals. I want them to practise their pharmacy role holistically rather than settling for mere competence at this skill or that task. I want them to make good-quality, well-reasoned patient care decisions without labouring at it forever. I want them to see what is most important in a patient care situation and act confidently within their scope of practice to rectify what can be changed. I want their practice to be guided more by maxims than by rote application of rules. I want them to be change agents, and I want them to glimpse a vision of what expert practice could be.

Can this be done in a 1-year residency? Education theorists tell us that the rate of progression to competent, proficient, and, eventually, expert practice varies from person to person. Whether the progression takes 2 months, 1 year, 10 years, or an entire career is influenced by the individual's attitude, aptitude, experiences, motivation, role complexity, personal ability to apply reflection-in-action, and access to feedback during practice. ${ }^{2,3,7-11}$ Modern pharmacy practice residencies are designed to achieve progression to or beyond a specified level of skill by providing organized learning experiences; feedback during practice; preceptorship to address attitude, aptitude, or motivational barriers; and mentorship that prompts reflection-in-practice. ${ }^{4}$ The evidence speaks for itself. Surveys and essays have told us that although residents value the 1-year residency program for the expanded clinical knowledge they acquire, they value it even more for the opportunity to gain practical knowledge, insight, artistry, judgment, know-how, emotional control, self-confidence and self-knowledge. ${ }^{12,13}$ They acknowledge residency programs for guiding them during the transition from theory to practice, for helping them to grow an entrepreneurial spirit and persevere despite the opposition that is so often directed at change leaders, for helping them to learn to accept and give care, and for encouraging them to have the courage to test their limits. ${ }^{14,15}$

That is what we know we have accomplished during a 1-year residency program to this point. Could the same outcomes be achieved in less than 1 year? That experiment has not yet been performed. Would progression to greater levels of skill be assured if residencies were longer than 1 year in duration? Possibly, but I genuinely believe that that would be a different residency. A residency beyond 1 year, one that aims to achieve professional proficiency for all competencies and/or expertise among selected (e.g., direct patient care) competencies might more appropriately be called a specialized residency. And what would be the motivations for moving the bar, so to speak, to expect "proficient" or even "expert" instead of "competent" as the minimum skill level at which a pharmacist is prepared to engage in practice (a shift that would require entry-level preparation to be grounded at the competent level and might also imply a need to mandate residency training for pharmacists working in direct patient care roles)? Such topics deserve further debate.

Is a 1-year pharmacy residency adequate to prepare pharmacists to engage in practice? Given that the purpose of a modern 1-year pharmacy practice residency is to refine professional competence and achieve proficiency in direct patient care, my answer is a resounding "Yes". 


\section{References}

1. Association of Faculties of Pharmacy of Canada, Advisory Committee on Curricular Change. Development of levels and ranges of educational outcomes expected of baccalaureate graduates. Vancouver (BC): The Association; 1999 [cited 2008 Nov 11]. Available from: http://www.afpc.info/downloads/1/Educational_Outcomes_1999.pdf

2. Dreyfus HL, Dreyfus JE. Mind over machines: the power of human intuition and expertise in the era of the computer. New York (NY): Free Press; 1985.

3. McGaghie WC. Evaluating competence for professional practice. In: Curry L, Wergin JF, editors. Educating professionals: responding to new expectations for competence and accountability. San Francisco (CA): Jossey-Bass Publishers; 1993. p. 229-261.

4. Accreditation standards 2010. Ottawa (ON): Canadian Hospital Pharmacy Residency Board. Forthcoming.

5. 2010 accreditation standards workshop proceedings: levels and ranges document draft v2. Ottawa (ON): Canadian Hospital Pharmacy Residency Board; 2008 [cited 2008 Nov 11]. Available from: http://www.cshp.ca/ programs/residencyTraining/CHPRBinfo_e.asp

6. Batalden P, Leach D, Swing S, Dreyfus H, Dreyfus S. General competencies and accreditation in graduate medical education: an antidote to overspecification in the education of medical specialists. Health Aff 2002;21(5):103-111.

7. Benner P. From novice to expert: excellence and power in clinical nursing practice. Menlo Park (NJ): Addison-Wesley; 1984.

8. Eraut M. Developing professional knowledge and competence. London (UK): Falmer Press; 1994.

9. Campagna KD. Pharmacists' levels of performance in making drug therapy decisions. Am J Health Syst Pharm 1995;52(6):640-645.

10. Campagna KD, Newlin MH. Key factors influencing pharmacists' drug therapy decisions. Am J Health Syst Pharm 1997;54(11):1307-1313.

11. Schon DA. The reflective practitioner: how professionals think in action. New York (NY): Basic Books; 1983

12. Pierpaoli PG. Mentoring. Am J Hosp Pharm 1992;49(9):2175-2178.

13. Haines ST. Making residency training an expectation for pharmacists in direct patient care roles. Am J Pharm Educ 2007;71(4):71.

14. Bucci KK, Knapp KK, Ohri LK, Brooks PJ. Factors motivating pharmacy students to pursue residency and fellowship training. Am J Health Syst Pharm 1995;52(23):2696-2701.

15. Moy D, Musing E. Canadian pharmacy practice residencies: a learning needs assessment. Can J Hosp Pharm 2003;56(5):259-266.

Donna M M Woloschuk, BSP, PharmD, MDE, FCSHP

Regional Pharmacy Manager-Education Services

Winnipeg Regional Health Authority

Clinical Assistant Professor

Faculty of Pharmacy

University of Manitoba

Winnipeg, Manitoba

Note: Portions of this manuscript were taken from an essay submitted by the author on November 30, 2003, in partial fulfillment of the requirements for the Master of Distance Education program, Athabasca University, Athabaska, Alberta. The author is a past chair and current member of the Canadian Hospital Pharmacy Residency Board. However, the views expressed in this article are those of the author and are not intended to represent the official position of the Canadian Hospital Pharmacy Residency Board.

\section{THE "CON" SIDE}

Traditionally, hospital pharmacists have been leaders in the profession in terms of providing patient-centred care and working as part of interprofessional teams. The 1-year post-baccalaureate hospital pharmacy residency program, introduced in the late 1960 s, was designed to produce skilled hospital pharmacy practitioners. Although the structure, quality, and standards of residency programs have evolved over the years, it is time to re-evaluate whether a 1 -year residency program is long enough to prepare pharmacists for hospital practice. The vision for pharmacy in Canada, the importance of clinical mastery, deficiencies in Canadian residency training programs, and the experience of our counterparts in the United States clearly point to the need for longer pharmacy residency training.

The need to expand pharmacists' roles as part of health care delivery is recognized in Canada. Expanded scopes of practice and legislation to enable prescribing activities in some provinces reflect a greater emphasis on the pharmacist's role in promoting safe and effective medication use. The recent Blueprint for Pharmacy: The Vision for Pharmacy ${ }^{1}$ states that pharmacists will "manage drug therapy in collaboration with patients, caregivers, and other health professionals" and will take responsibility for drug therapy decisions. To achieve this vision, additional experiential training of pharmacists, including hospital pharmacists, is required.

The basic premise of residency training is to develop "clinical maturity". ${ }^{2,3}$ This attribute involves having the core skills and knowledge, as well as the confidence, to function as an autonomous practitioner. Residency training provides the scaffolding for the bridge between theory and practice. Mastery is achieved through repetition, and performance is refined through reflection. ${ }^{4}$ The question is, does a 1-year residency program provide enough opportunity for pharmacy residents to practise the skills necessary for direct patient care in a variety of settings? We believe it does not, especially in the current practice environment. Pharmacy practice has changed dramatically since the first residency programs were established in Canada over 40 years ago. Practice today involves an increasingly complex health care environment, diverse practice areas, and an aging population. Improvement in medication options for disease management means that patients who at one time would have been cared for in the hospital are now treated in the community or ambulatory settings; as a result, the level of acuity for inpatients has increased dramatically. In addition, expanded scopes of practice and prescribing privileges have opened the door for pharmacists to have increased responsibility and accountability for patient care. Our profession is on the verge of a cultural shift whereby pharmacists are becoming independent practitioners; as such, we need to prepare our residents to function in this capacity.

Deficiencies in current residency programs also point to the need to increase the length of training. The reality is that residents spend only $50 \%$ to $60 \%$ of their time in direct patient care rotations during the year. The remainder of the year consists of drug distribution, practice management, drug information, and research rotations. Others have expressed concern regarding the need for more direct patient care experiences. $^{5,6}$ In 2001, in a survey of 137 recent graduates from Canadian pharmacy residency programs, $73 \%$ of respondents were interested in having more time devoted to a wider variety of clinical rotations. ${ }^{6}$ The majority felt this could be accomplished by restructuring the residency year, with less time in nonclinical functions. It is questionable, however, whether redesigning the residency year is enough. We also need to consider what skills we would sacrifice by eliminating nonclinical rotations. The purpose of the pharmacy practice residency, as outlined by the Canadian Hospital Pharmacy Residency Board (CHPRB), is "to refine professional competence in direct patient care, to refine personal practice skills and to develop leadership skills that can be applied in any position and in any practice setting". What would be lost if residents were not given the opportunity and time to develop leadership or practice management skills? Residency programs have been 
the cornerstone of "developing future leaders for the growth of our profession". ${ }^{7}$ In North America, we are facing a management crisis due to a lack of pharmacy leaders. ${ }^{8}$ In addition, the lack of development of formal teaching skills has been identified as a deficiency with many residency programs. ${ }^{6,9}$ In a survey published in 2006, only about one-quarter of the 25 Canadian residency coordinators incorporated a teaching component into their respective programs. ${ }^{9}$ Thus, extending the residency program is necessary to develop direct patient care skills, as well as other skills such as leadership and teaching.

Trends in undergraduate pharmacy education, in both the United States and Canada, also point to the need for changes in residency training. Since 2000, all pharmacy schools in the United States have moved to entry-level PharmD degrees. Several Canadian schools have either pursued or are considering moving to an entry-level PharmD degree as well. While the PharmD program increases direct patient care opportunities, additional training is still required to adequately prepare hospital pharmacy practitioners. The new accreditation standards of the American Society of Health-System Pharmacy (ASHP) have replaced pharmacy practice residencies with postgraduate year 1 (PGY1) pharmacy residencies and specialized residencies with postgraduate year 2 (PGY2) pharmacy residencies. ${ }^{10}$ A PGY2 pharmacy residency is designed to build upon competencies developed by a PGY1 pharmacy residency program. This additional year of residency training gives practitioners the knowledge, skills, and confidence to practice autonomously and to assume responsibility for patient care upon completion.

Extending pharmacy residency training in Canada would have several benefits. Longer rotations (i.e., beyond the traditional 3- to 4-week rotations) would provide the opportunity to integrate and build knowledge and skills to more complex levels. Residents could be exposed to diverse practice settings and become familiar with the complexity of the health care system. Longer rotations would also allow residency training experiences to be individualized, including selection of specialization areas. Core training could be accomplished in the first year, and the second year could be tailored to match the resident's career plans, as well as providing a transition to more independent function. In addition, more time could be devoted to developing teaching skills. A "stacked" approach similar to the medical model could be employed, with second-year residents mentoring first-year residents, and first-year residents mentoring pharmacy undergraduate students under the guidance of an experienced pharmacy preceptor. ${ }^{11}$
Although the challenges to increasing residency training include potential shortages of qualified preceptors and a requirement for additional resources, the need to expand residency training is clear. As Albert Einstein once said, "the only source of knowledge is experience".

\section{References}

1. Canadian Pharmacists Association, Task Force on a Blueprint for Pharmacy. Blueprint for pharmacy: the vision for pharmacy. Ottawa $(\mathrm{ON})$ : The Association; 2008.

2. Ray MD. Clinical maturity in pharmacy. Pharmacotherapy 2006;26(5):594-596.

3. Haines ST. Making residency training an expectation for pharmacists in direct patient care roles. Am J Pharm Educ 2007;71(4):Article 71.

4. Ericsson KA. Deliberate practice and acquisition of expert performance: a general overview. Acad Emerg Med 2008;15(11):988-994.

5. Executive of the Hospital Pharmacy Residency Forum of Ontario. Position paper on the role of hospital residency programs in clinical training and professional development in the era of the proposed entry-level doctor of pharmacy program. Can J Hosp Pharm 2006;59(4):210-213.

6. Moy D, Musing E. Canadian pharmacy practice residencies: a learning needs assessment. Can J Hosp Pharm 2003;56(5):259-266.

7. Pierpaoli PG, Flint NB. Residency training - the profession's forge for leadership development. Pharm Pract Manag Q 1998;15(2):44-56.

8. White SJ. Will there be a pharmacy leadership crisis? An ASHP Foundation Scholar-in-Residence report. Am J Health Syst Pharm 2005;62(8):845-855.

9. Gerber P. Pharmacy residents developing teaching skills during the pharmacy practice residency program: a closer look at the issue. Can J Hosp Pharm 2006;59(1):14-21.

10. Teeters J. New ASHP pharmacy residency accreditation standards. Am J Health Syst Pharm 2006;63(11):1012, 1014, 1018.

11. Bartle B. Graduating a more confident pharmacist: applying the medical model of training [editorial]. Can J Hosp Pharm 2005;58(3):127-128.

Nese Yuksel, BScPharm, PharmD, ACPR, FCSHP

Christine A Hughes, BSCPharm, PharmD, ACPR, FCSHP

Faculty of Pharmacy and Pharmaceutical Sciences

University of Alberta

Edmonton, Alberta

\begin{tabular}{lll}
\multicolumn{3}{c}{ Advertisers ' Index } \\
\hline \\
\hline Astellas / Ambisome & Ad Page & Prescribing Information \\
\hline Boehringer-Ingelheim / Pradax & 2 & $55-57$ \\
\hline Manrex Ltd. / Corporate & 4,5 & $58-61$ \\
\hline The Medi-Dose Group / Corporate & 6 & - \\
\hline Pharmaceutical Partners of Canada / Adenosine & 9 & - \\
\hline $\begin{array}{l}\text { Pharmaceutical Partners of Canada / } \\
\text { Piperacillin-Tazobactam }\end{array}$ & OBC & 62,63 \\
\hline Sandoz / Corporate & IFC & $50-54$ \\
\hline
\end{tabular}

